\title{
O RESPEITO À DIVERSIDADE CULTURAL-RELIGIOSA PELO CARÁTER DE LAICIDADE DO ESTADO: UMA CRÍTICA HERMENÊUTICA AO ENSINO CONFESSIONAL NA ESCOLA PÚBLICA
}

\author{
Claudine Rodembush Rocha ${ }^{1}$ \\ Henrique Alexander Grazzi Keske ${ }^{2}$
}

\begin{abstract}
RESUMO: O presente artigo tem foco na discussão acerca do caráter de laicidade do Estado brasileiro, erigido como norma constitucional, enquanto forma de se garantir o equilíbrio da complexidade performativa cultural-religiosa de nossa sociedade. Para tanto, através do método de pesquisa bibliográfica, apresenta uma análise acerca do que denomina de hermenêutica da diversidade, para evidenciar a necessária mudança paradigmática a se operar, tanto nos níveis de jurisdição do próprio Estado; e alerta para as injunções legislativas de grupos religiosos específicos, bem articulados na esfera pública, capazes de interferir negativamente, agredindo o caráter laico, ou seja, neutro do Estado.
\end{abstract}

Palavras-chave: Diversidade; Ensino Confessional; Escola Pública; Hermenêutica; Laicidade.

\section{RESPECT FOR CULTURAL-RELIGIOUS DIVERSITY FOR THE CHARACTER OF SECULARITY OF THE STATE: A HERMENEUTIC CRITIQUE OF CONFESSIONAL TEACHING IN THE PUBLIC SCHOOL}

\begin{abstract}
The present article discusses the secular character of the Brazilian State, erected as a constitutional norm, as a way of guaranteeing the balance of the cultural-religious performative complexity of our society. Through the method of bibliographical research, it presents an analysis about what it denominates of hermeneutics of the diversity to evidence the necessary paradigmatic change to operate in the levels of jurisdiction of the State itself; besides alerting to the legislative injunctions of specific religious groups, well-articulated in the public sphere, capable of interfering negatively, attacking the secular character, that is, neutral of the State.
\end{abstract}

Keywords: Hermeneutics; Diversity; Secularism; Confessional Teaching; Public School.

\footnotetext{
${ }^{1}$ Doutora em Direito pela Universidade de Burgos-Espanha, Mestre em Direito pela Universidade de Santa Cruz do Sul - UNISC, Pós-graduada em Demandas Sociais e Políticas pela Universidade de Santa Cruz do Sul - UNISC, Advogada, Professora do Curso de Direito da Faculdade Estácio do Rio Grande do Sul. E-mail: claudinerodembusch@yahoo.com.br.

${ }^{2}$ Doutor em Filosofia pela Universidade do Vale do Rio dos Sinos - UNISINOS, Mestre em Filosofia pela Pontifícia Universidade Católica - PUC/RS. Advogado. Professor de Direito da Universidade Feevale. E-mail: henriquek@feevale.br
} 


\section{CONSIDERAÇÕES INICIAIS}

O presente artigo, com foco no que se poderia denominar de uma hermenêutica da diversidade, tem por pressuposto se experienciar o Direito enquanto um dos modos mais genuínos da própria existência humana, apresentando os desafios de se interpretar o Direito, para bem poder aplicá-lo, de forma que se fundamenta na corrente doutrinária que se alinha com a afirmação de que ambos os processos, ou seja, de interpretação e aplicação não podem mais ser pensados e exercidos de maneira separativa, como se somente o texto da norma pudesse ser interpretado mediante o emprego de métodos científicos especificamente elaborados para tal fim. A hermenêutica jurídica se entende, aqui, em seu aspecto mais amplo, no sentido de seu emprego na produção mesma do Direito, desde a interpretação dos fatos a serem transformados em norma jurídica pelo legislador, até a interpretação dos julgadores para aplicá-la aos casos concretos em lide.

Desde que se pense o Direito enquanto doutrina, norma e jurisprudência, se está, desde o princípio, articulando-se no nível de interpretação, pondo-se, dessa forma, a descoberto, a superação do velho brocado jurídico de que, com o texto claro, já não existe necessidade de interpretação. Esse processo como um todo, envolvendo cada uma de suas etapas, se constitui em verdadeira forma de se operar uma integração do Direito, na busca por uma superação das falhas sistêmicas que se apresentam quando de sua aplicação, mormente quando nos defrontamos com a enorme diversidade cultural formadora de nosso país, mais especificamente ainda quando tal caráter diverso se evidencia nos aspectos religiosos manifestados em nossa cultura, marcada por essa diversidade constitutiva.Eis o desafio hermenêutico de uma sociedade constitutivamente marcada pela diversidade; ou seja, não considerar mais a possibilidade de que exista somente um sentido único a ser erigido como determinação absoluta de um fazer, ou não fazer, seja qual for; mesmo que esta postura possa implicar em uma outra forma de se pensar e exercer a segurança jurídica não focada no monopólio de nenhum dos intérpretes de tais normas.

Estas considerações iniciais, a seu turno, são focadas na recente decisão do Supremo Tribunal Federal, no sentido de permitir o estudo confessional na escola pública, aqui considerada como uma agressão ao caráter do Estado laico erigida como norma constitucional em nosso ordenamento. Ainda que tal decisão seja voltada para o caráter opcional desse ensino 
para quem o recebe, torna-se obrigação do Estado oferecer essa possibilidade a quem dela quiser usufruir; ou seja, o Estado deve contratar professores pagos por verba pública para atender a esses anseios de ensino religioso, em todas as suas variáveis. Assim, surge o problema de se manter a laicidade do Estado, no momento em que, em função do histórico predomínio da religião católica e da mais recente organização das Igrejas alinhadas com o denominado neopentecostalismo, se poderia operar a transformação da escola pública em espaço para o aliciamento de fiéis, bem como relegar à condição de inferioridade os outros cultos religiosos no Brasil, de viés oriental e, notadamente, da grande gama de religiões de matriz africana, as quais já padecem de um histórico de segregação e descaso.

De outra parte, respeitar a laicidade erigida como norma constitucional, passa por considerarmos a Constituição a partir de seu caráter próprio, ou seja, como norma a ser cumprida e a se irradiar para o conjunto do ordenamento. Com essa postura doutrinária ativa, se poderia dar uma resposta ao solipsismo das decisões judiciais, bem como contra as tentativas de grupos religiosos organizados no Poder Legislativo, de imporem seus postulados religiosos como verdades erigidas em forma de lei, contra mesmo a própria diversidade cultural constitutiva de nosso país.

\section{HERMENÊUTICA DA DIVERSIDADE: DESAFIOS DE INTERPRETAR E APLICAR O DIREITO}

Existe um aforisma muito antigo e ainda repetido, mas que já se encontra completamente superado quando se trata de questões ligadas à hermenêutica jurídica, mais precisamente quando se procura evidenciar a intrínseca relação entre interpretação e aplicação do Direito, consubstanciado na fórmula: in claris cessat interpretatio, ou seja, perante a clareza da lei, cessa a interpretação. Este brocado, que soa, ainda, como um resquício medieval, traz, em si, a possibilidade que, agora, na contemporaneidade, já não se considera mais como revestida desse caráter de objetividade, no sentido de que existiriam textos jurídicos que pudessem ser aplicados, de maneira imediata, sem que, concomitantemente com a aplicação, fossem objeto de interpretação; porque outro paradigma já assevera que não há interpretação sem aplicação do Direito, bem como não existe aplicação do Direito, sem interpretação. 
A enunciação anterior refere-se, logo, a uma antiga forma utilizada pelos primeiros doutrinadores, preocupados com segurança jurídica, com o intuito de castrar o poder de interpretação dos Juízes, inclusive com alguns códigos que proibiam, expressamente, a ação interpretativa dos Magistrados, mas que, em decorrência da realidade prática, evidenciou a impossibilidade de sua aplicação radical, já que toda a manifestação jurídica, da forma que for apresentada, seja clara, ou obscura, perfeita ou imperfeita, é passível de interpretação. E aqui está lançado o desafio: se assim é, fica a questão fundante do problema - de que forma proceder para se eliminar, ou, pelo menos, minimizar a possibilidade de uma decisão subjetiva que, ao aplicar a norma, extrapole, completamente, o que a norma diz em seu texto? (VENOSA, 2014, p. 152).

A seu turno, quando apresenta os problemas advindos dessa relação, Carlos Maximiliano, adverte, em sua obra Hermenêutica e aplicação do Direito, que o desafio se estabelece quanto à aplicação, dado que a dificuldade está em se poder estabelecer a conexão entre o caso concreto, trazido à lide, em confronto com a lei abstrata, editada de maneira genérica, para que se possa, de maneira objetiva, vislumbrar os modos e os meios de se preservar os interesses jurídicos que estão sendo debatidos. Assim, o Direito dado na norma deve adaptar-se à realidade efetiva, tanto do ponto de vista individual, de seus postulantes e contentores, quando em seus aspectos coletivos, no sentido do interesse social, que não pode ser dissociado da aplicação do Direito. Nesses casos, é preciso se precaver contra a possível violação das normas e, ao mesmo tempo, evitar que, pelos operadores do Direito, Juízes e Tribunais, se chegue a uma aplicação arbitrária, ou forçada dessa relação. Por conta disso, se surge mais de um preceito aplicado ao caso, com regras que se chocam ou se embaralham, inicia-se a busca para que se identifique a regra mais adequada: assim, tem início a busca pelo grupo de tipos jurídicos que, de maneira geral, apresentem similaridade com o fato em análise para, depois, se poder reduzir o problema a se investigar somente aos que revelam maior proximidade, ou que se possa equiparar com o caso em tela. Depois disto, uma vez verificado o ramo do Direito onde se possa localizar a solução do caso, o aplicador seguirá para o exame das prescrições especiais, as quais podem, por sua vez, apresentar colisão, o que determina o exame prévio do Direito Constitucional. Logo, em todas essas etapas, para se chegar a termo na aplicação, já se está operando no nível da interpretação. (MAXIMILIANO, 2013, p. 5-6).

No sentido de procurar evidenciar os problemas decorrentes do que se denomina de enquadramento dos fatos às normas, para promover a adequada solução da lide, enquanto uma 
hermenêutica que implique no caráter concomitante que se estabelece entre interpretação e aplicação do Direito; pode-se afirmar que:

\begin{abstract}
No âmbito da interpretação jurídica, ou seja, no substrato constituído pelos enunciados prescritivos que formam a base do Direito, a hermenêutica é uma espécie de gênero denominado interpretação em função normativa, pois consiste em um processo de atribuição de sentido aos enunciados de textos ou normas que compõem o ordenamento jurídico, visando à resolução de um caso concreto. Tem por finalidade precípua elevar, para o plano da racionalidade, os fatos sociais dotados de um significado valorativo, aproximando-os e confrontando-os com as hipóteses legais previamente estabelecidas, no intuito de correlacionar esses dois planos da realidade, em busca de sua adequação ou inadequação. (CANFÃO, 2013, p. 06).
\end{abstract}

Quando trata dessa questão hermenêutica, Limongi França traz outra advertência, no sentido de considerar o problema que se estabelece ao se aplicar as normas positivas, elaboradas previamente e, logo, de maneira abstrata, aos casos concretos; pois as referidas normas não são capazes de abranger, em suas determinações, a especificidade do que se está a discutir na lide, de modo que:

\footnotetext{
Quando se fala de hermenêutica ou interpretação, advirta-se que elas não se podem restringir tão somente aos estreitos termos da lei, pois conhecidas são suas limitações para bem exprimirem o direito, o que, aliás, acontece com a generalidade das formas com que o direito se reveste. Desse modo, é ao direito que a lei exprime que se devem endereçar, tanto a hermenêutica, como a interpretação, num esforço de alcançar aquilo que, por vezes, não logra o legislador manifestar com a necessária clareza e segurança. (FRANÇA, 1999, p. 04).
}

Antônio Betioli, ao se debruçar sobre os âmbitos próprios que relacionam a aplicação do Direito à sua concomitante interpretação, amplia o sentido dessa relação, acrescentando o caráter de que esse relacionar-se se consubstancia em uma ação integradora do Direito, de forma que tais etapas compõem um processo único e contínuo, cujo objetivo consiste na própria produção do Direito; dado que tais processos têm uma forte correlação, uma vez que, se o Direito existe, ele é aplicado, entretanto, anteriormente e para tanto, foi interpretado, sendo que só poderá haver uma aplicação satisfatória, se a interpretação também o tiver sido. Esse problema se torna mais agudo ainda, quando se está diante de lacunas da lei, ou no desamparo da lei expressa, ou seja, na ausência da lei, quando se torna necessária uma resposta jurídica que seja favorável ou não ao caso concreto. Este processo unitário é que se denomina de integração do Direito: assim, interpretação, aplicação e integração do Direito são processos que 
não se separam, mas, sim, se unem em um movimento não linear, ou seja, como âmbitos concomitantemente auto-constitutivos. (BETIOLI, 2011, p. 375-76).

Nesse sentido, o caráter mais amplo dado às possibilidades da hermenêutica jurídica se origina, a seu turno, em uma mudança de paradigma operada na forma do pensar ocidental, a partir dos contributos de Heidegger, através da Filosofia Hermenêutica, bem como na Hermenêutica Filosófica de Gadamer, que irá produzir esse novo enfoque no enfrentamento do problema da interpretação e aplicação do Direito. Assim, para o enfoque do presente artigo, basta que se evidencie que Heidegger propõe uma forma de se repensar a metafísica da tradição filosófica, ao não separar o ser que conhece do objeto que este se dispõe a conhecer, ao afirmar que o processo de conhecimento se estabelece a partir de uma unidade originária, que denomina ser-no-mundo, ou ser-aí, em que essas instâncias não se apresentam separadas na existência, mas como âmbitos auto-constitutivos; e esta não separatividade ser e mundo é que se consubstancia como condição de possibilidade do próprio conhecimento, ou seja, não se pode separar o ser de seu mundo e vive-e-versa.

Aplicando-se tais postulados ao Direito se pode afirmar a intrínseca relação entre o mundo social que produziu a lei e sua posterior aplicação, que não podem ser pensados de forma isolada, ou seja, legislador e intérprete estão no mundo. Da mesma forma, de Gadamer se chega à afirmação de que interpretar se inscreve em um âmbito mais amplo, como um processo instaurador de sentidos, através do qual o ser humano amplia seu conhecimento, em círculos concêntricos, valendo-se de uma racionalidade não linear, mas que opera no íntimo do circulo da compreensão, em que a figura do intérprete se relaciona constitutivamente com o mundo no qual se encontra inserido e que o constitui, a partir de uma pré-compreensão. Isto significa que aplicar a norma não se refere à mera interpretação de textos legais, mas à profunda instauração dos sentidos legais erigidos como normas jurídicas.

Por conta disso, é que o sentido anteriormente atribuído à hermenêutica jurídica, pelo paradigma anterior, era bastante restrito, pois era considerado somente como esse conjunto de métodos para se encontrar os verdadeiros sentidos de um texto legal. Assim, afirmava-se que o intérprete viesse a atingir um ponto de neutralidade em sua atividade de aplicar a norma jurídica, presumindo-se que a atividade do intérprete, a partir da interpretação, poderia encontrar no texto, o sentido único, que apresentava como já dado pelo legislador; sentido esse que já estaria ali. O problema se forma, porém, no momento em que, embora essa concepção já esteja vencida pela doutrina, até mesmo por doutrinadores positivistas, como Kelsen e Hart, ela 


\section{O RESPEITO À DIVERSIDADE CULTURAL-RELIGIOSA PELO CARÁTER DE LAICIDADE DO ESTADO: UMA CRÍTICA HERMENÊUTICA AO ENSINO CONFESSIONAL NA ESCOLA PÚBLICA}

ainda é defendida e sustentada pelos aplicadores do Direito. (SILVA, 2005, p. 276). Entretanto, o que se percebe pela articulação desse novo paradigma, é que todo o aplicador, no momento de realizar sua tarefa, já vem influenciado pelas condições próprias do mundo de sentidos que o constituiu em sua existência e que não pode afastá-lo, como para atingir uma neutralidade absoluta e imparcial, nem mesmo tem a possibilidade de acessar os fatos em lide em uma espécie de clara transparência objetiva do real.

Nessa atividade de aplicar o Direito, a partir da intrínseca interpretação que a precede, surge a circunstância de que esse indivíduo-intérprete compreende-se a si mesmo por meio da compreensão dos fatos postos a exame; bem como relaciona os âmbitos de si mesmo e dos fatos examinados a partir de sua situação histórica, entendendo-se por situação os conceitos prévios de que é portador, isto é, que o formaram. Assim, seu ponto de partida é a tradição a que pertence e, em consequência, isto lhe faz projetar um horizonte de sentidos, como aquilo que tem condições de focar, na medida em que se dirige a aplicar o Direito na dada circunstância concreta que lhe foi submetida: ou seja, todo o ser histórico encontra-se inserido em dada tradição e, concomitantemente, ocupa determinada posição que lhe aponta e, ao mesmo tempo, lhe delimita um certo horizonte perceptivo.

Nesse enfoque, logo, horizonte nada mais é do que o campo ou a extensão daquilo que o homem compreende e, portanto, que o auxilia a compreender-se a si mesmo, em confronto com a situação concreta que lhe foi lançada em sua direção, pela própria existência. Entretanto, a história humana não é estanque, mas se refere a um fluxo contínuo de eventos em um processo igualmente contínuo de instauração de sentidos, de forma que, nessa mobilidade permanente, os horizontes também se distendem, a partir daquele momento histórico a que o homem, inicialmente, se encontra vinculado. Em função disto, não se pode falar em um único sentido, ou em um único horizonte a se descortinar a partir dessa situação histórica. Assim, horizonte e historicidade se movem conforme quem se move. (CAMARGO, 2011, p. 32).

Nesse passo, forma-se a controvérsia relativamente à condição de que esse intérprete (e, poderíamos acrescentar, esse operador do Direito, em quaisquer de suas funções), encontrase como que atingido, em suas apreciações, por essas preconcepções que carrega consigo, haja vista que, integrando uma determinada tradição, seja religiosa, filosófica ou ideológica, de quaisquer naturezas, irá aplicar o Direito a partir delas, ou seja, fará com que tais pré-convicções tenham efeitos diretos na forma de interpretação e compreensão, tanto do fato, quanto do texto 
legal que sobre ele fará incidir, para solução da lide. Nessa linha do pensar hermenêutico,não há como dissociar o intérprete dessa tradição a que pertence, pois este intérprete é ser-nomundo, isto é, não está isolado de seu mundo, não pode se apartar de seu mundo de sentidos, ou seja, não se pode segregar o homem do universo em que está inserido e que o constitui enquanto tal, pois ser e mundo são instâncias auto-constitutivas da própria percepção do que se possa compreender como realidade. (SILVA, 2005, p. 276-296).

Esta forma do pensar hermenêutico se aplica, portanto, não apenas ao Juiz, apesar de que, a este com certeza se aplica, pois este operador do Direito, a seu turno, não se segrega, por inteiro do mundo de sentidos que integra sua tradição de pertencimento; mas, também se aplica ao legislador, dado que este, ao praticar sua atividade normativa, igualmente não se afasta de seu próprio sentido de interesse nessa atividade. Desse modo, é que, como referido, estão atingidos, pela base, os mitos de imparcialidade e neutralidade, tanto do julgador, quanto do legislador.

Podemos retomar, agora, o contexto da já referida virada paradigmática operada a partir desse novo enfoque hermenêutico-linguístico, trazendo-o para um aporte da hermenêutica jurídica, na medida em que essa intrínseca relação entre norma e texto legal, bem como a questão do sentido que lhes deva ser atribuído, pode levar as possibilidades interpretativas para vários caminhos; no entanto, todas essas possibilidades estão baseadas no fato de que o homem está inserido no mundo, bem como nas condições de possibilidade em que tem acesso a esse mundo de sentidos instaurados. Por conta disso, surge a necessidade de se criarem regras que possam guiar o intérprete durante o processo interpretativo, dado que se reconhece que há uma pretensa fragmentação entre o ato de conhecimento do texto legal e sua posterior aplicação a um caso concreto. Entretanto, nesse outro enfoque, se reconhece que ambas as instâncias caminham juntas, ou seja, interpretar e aplicar se constituem reciprocamente. Não se pode mais, portanto, se colocar os problemas hermenêuticos em nenhum desses polos fixos da relação de conhecimento, ou seja, nem na subjetividade do intérprete, nem mesmo na pretensa clareza e objetividade do texto normativo, pois essa divisão não passa de uma falsa contraposição fundada no metafísico esquema sujeito-objeto, já superada por esse novo aporte teórico. (STRECK, 2007, p. 29-46).

Quando se discute o tema ligado a essa virada paradigmática que ampliou o alcance da hermenêutica, que deixa de ser considerada apenas como um conjunto de métodos capazes de assessorar o julgador na interpretação do texto da lei para que, assim, possa melhor aplicá- 
la, de forma a ser considerada em sua real extensão, enquanto produção do Direito; exsurge 0 problema dos limites a que se deve fazer referência a essa atividade decisória dos Juízes, dado que, ao ampliarem os sentidos das leis, acabam, em verdade, produzindo decisões como normas jurídicas, só que, constitucionalmente, não estão habilitados ao processo legislativo: esse fenômeno vem sendo estudado e definido como protagonismo e/ou ativismo judicial. Assim, um dos maiores críticos dessa postura é, precisamente, Lênio Steck, a partir do que define como uma Crítica Hermenêutica ao Direito. Nesse sentido, é interessante notar, em função da proposta do presente artigo, a exposição que o autor realiza na obra Hermenêutica e Jurisdição, notadamente na parte que se refere à decisão judicial e a realidade brasileira, quando interpelado pelo Juiz Federal Bianor Arruda Bezerra Neto, quanto ao tema do protagonismo judicial, como um fenômeno que surge no direito brasileiro mesmo antes da Constituição Federal /88:

\footnotetext{
Sim, é realmente anterior. Como disse, o Estado era autoritário, o direito era ruim, e a sociedade complexa demandava que esse direito fosse, digamos assim, reaproveitado. As pessoas têm que entender que são questões históricas. Nós precisávamos do realismo jurídico. (...) É o que podemos chamar, também, de empirismo jurídico. (...) Qual o problema, então? O problema está na continuidade do protagonismo judicial numa configuração democrática. Insisto que ativismo e democracia não se coadunam. Ativismo está relacionado ao despotismo do sujeito moderno, para fazer uma alusão aos paradigmas filosóficos. (STRECK, 2017, p. 153).
}

Realmente, uma breve análise, em relação ao tema religioso, acerca da decisão judicial em comento, determinando o estudo confessional na escola pública, pode mostrar que tais disposições oscilam, ora reafirmando a neutralidade do Estado, ainda que de maneira formal, distante da práxis de aplicação das normas pelos próprios órgãos desse Estado. Essa precariedade democrática, redundando em leis de sentidos ambíguos, ensejou, historicamente, esse Juiz mais autoritário, preocupado com a segurança jurídica, entendida como a necessidade de estabelecer um sentido único às normas, para solucionar os casos concretos. Entretanto, no momento em que se pretende viver sob a égide de um Estado Democrático de Direito, essa decisão autoritária dos Julgadores não se pode mais sustentar, em situações nas quais o Juiz protagoniza suas decisões para muito além das determinações legais. Outro enfoque, porém, deve-se deixar em destaque, na forma de uma questão impactante para o enfoque do presente artigo: o próprio processo legislativo é, realmente, democrático, ou estamos enfrentado o problema de que muitas das leis se referem a tão-só a perspectiva de grupos de interesses que 
lançam como norma seus postulados morais e /ou religiosos, a fim de submeterem a vontade geral?

Portanto, eis aqui o desafio hermenêutico, que se forma pós-Constituição/88, em que esse Juiz autoritário deveria ceder seu lugar a esse novo paradigma democrático, a exigir do julgador que compreenda a própria constituição como norma a ser aplicada e, no caso em comento, em que a laicidade do Estado deve ser aplicada, como norma jurídica, a todo o nosso ordenamento. Não se trata de um texto que apresenta apenas delineamentos morais, como princípios, apenas, mas de um conjunto de deveres e obrigações, como uma prática normativa, como um conjunto de normas que irradiam, a partir de si, o dever de agir de acordo com suas prescrições, isto é, com as determinações que a própria Constituição estabelece. Portanto, essa mudança de paradigma, chega mais tarde ao Brasil, que, agora, a seu turno, deve confrontar-se com seus próprios limites, para que o próprio julgador compreenda que essa possibilidade aplicativa da própria Constituição não o leve a decidir como se detivesse, ainda, o monopólio da própria interpretação/aplicação do Direito, desassociando-o de seu contexto cultural e social mais amplo.

Assim, na esteira da discussão acerca dos limites a serem respeitados em função da atividade decisória do Juiz, Bianor Neto sinaliza que deve ocorrer uma mudança de atitude, da parte do próprio julgador, pois quando este vai decidir acerca de uma demanda que lhe foi apresentada, ele não pode, por exemplo, ali colocar as suas crenças. E dá como exemplo o fato de um Juiz que seja religioso, diante do caso concreto de julgar a possibilidade de aborto do feto anencéfalo. Nesse caso, se esse Juiz ou o representante do Ministério Público se coloca como um cristão fervoroso, provavelmente dirá: "só deus dá a vida e, portanto, só deus a tira”. Logo, tanto esse Juiz, quanto o representante do M.P. serão contrários ao aborto, no sentido de se manifestarem pela improcedência da demanda apresentada. O problema é que ele fará isso a partir de suas próprias crenças e valores e não através do Direito. Nesse passo, também poderíamos acrescentar: se este juiz for religioso, provavelmente, a partir de seus próprios valores, irá decidir, como, de fato decidiu, a favor do ensino religioso confessional na escola pública, ferindo, dessa maneira, o caráter de laicidade do Estado. Eis a resposta à provocação:

[...] Quando alguém ajuíza uma ação, não quer saber a opinião pessoal do atual ocupante do cargo. O que se demanda é uma resposta do "direito", da "estrutura". Buscamos uma resposta de fora do juiz, e não de dentro dele. É importante dizer isso, para ser bem claro e delimitar o problema representado pelo autoritarismo do sujeito da modernidade. (...) Por exemplo, nós construímos textos sobre seres históricos, construímos a Constituição, nós temos responsabilidades com a Constituição. Então, 
se eu tenho responsabilidade com a Constituição, mas, na hora H, eu aplico a minha concepção pessoal, aí entra o problema do solipsismo, ou de suas vulgatas. O solipsismo é um inimigo da democracia. Faz sentido, pois não? (STRECK 2017, p. 156).

Estas questões se revestem de importância, notadamente quando se discute a aplicação da própria Constituição. Entretanto, novamente se deve referir que o processo democrático deve ser efetivo e começar pelos próprios órgãos encarregados da atividade legiferante, dado que a lei pressupõe, em uma democracia representativa, que se está a respeitar a vontade geral, ou seja, da maioria da população que, por meio de eleições, delegou ao legislador seu próprio poder de legislar. Eis novamente o problema: isto não seria apenas uma idealização do processo de legislar? Em que medida esse legislador responde, mesmo, à vontade geral, ou, tão somente do segmento que lhe concedeu tal poder, ou à tradição religiosa de seu pertencimento? Em sua atividade legislativa se preocupa com o caráter de diversidade religiosa do país?

Por fim, na busca de uma solução para o problema até aqui tratado, acerca do protagonismo judicial, quando perguntado por Diego Ribeiro, editor do Blog Tribuna da Justiça, se haveria um modo de refrear esse ativismo, Streck assim se posiciona: Penso que o constrangimento epistemológico exercido pela doutrina é fundamental. O julgador deve se constranger ao tomar uma decisão fora dos parâmetros jurídicos (que é isso que constitui o ativismo). A doutrina deve voltar a doutrinar. Urgentemente. (STRECK, 2017, p. 162).

É nesse sentido que se insere a preocupação do presente artigo, ou seja, no fato de discutir, doutrinariamente, as questões ligadas à interpretação/aplicação do Direito, à luz de nossa diversidade cultural, principalmente no fato de que tal diversidade se refere, logo, a uma imensa diversidade religiosa, assegurada, no texto da Constituição, pela laicidade do Estado.Esse caráter de laicidade, entretanto, se vê combalida, tanto por decisões jurisprudenciais da mais alta Corte do país, como no caso do julgamento que permite o ensino confessional, ainda que opcional, dentro da escola pública; como pela atividade de grupos muito bem aparelhados, na máquina pública, notadamente entre os legisladores que, em sua atividade, se inscrevem, de forma permanente, em impor suas disposições morais, eivadas de postulados religiosos de suas agremiações específicas, como norma jurídica, à maioria da população.

\section{CARÁTER DE LAICIDADE DO ESTADO BRASILEIRO}


Dessa forma, qualquer abordagem acerca do caráter de laicidade do Estado brasileiro deve partir, obrigatoriamente, de uma análise constitucional, haja vista que se encontra consagrado como princípio, a partir do texto do art. 19, inciso I, da Constituição Federal/88; in verbis:

Art. 19. É vedado à União, aos Estados, ao Distrito Federal e aos Municípios: I - estabelecer cultos religiosos ou igrejas, subvencioná-las, embaraçar-lhes o funcionamento ou manter com eles, ou seus representantes, relações de dependência ou aliança, ressalvada, na forma da lei, a colaboração de interesse público.

Assim, o simples enunciado do texto remete, de pronto, a que, por óbvio, o Estado brasileiro não se define como confessional, ou seja, como erigindo determinado culto religioso como único, já que se refere à diversidade de quaisquer cultos, sendo-lhe expressamente proibido estabelecer quaisquer vínculos de dependência, ou mesmo de preferência em relação a estes. Merece, contudo, atenção especial, o dispositivo final, dado à sua natureza de cláusula aberta, ou seja, em que não se definem claramente as condições que ressalva, isto é, o significado e abrangência do que possa vir a ser o sentido de colaboração de interesse público, na forma da lei.

Ao comentar esses dispositivos, entretanto, Scalquette traz importante ressalva, no sentido de que, apesar do fato de que as Constituições republicanas brasileiras, de uma maneira geral, oscilarem em relação a tais princípios fundamentais, com algumas variáveis, restam estabelecidos, pelo menos sob o aspecto formal, essas condições do laicismo do Estado Brasileiro, apesar de que, na prática, tal caráter se reveste de relatividade, haja vista que:

Como o Estado é formado, dentre outros elementos, pelo Povo - reunião de pessoas e as pessoas, em sua grande maioria, são carregadas de religiosidade, ao serem editadas as leis dentro do Estado, elas acabam por projetar essa religiosidade, consequentemente, gerando uma laicidade não absoluta do Estado. (SCALQUETTE, 2013, p. 169).

Assim sendo, mesmo que movimentos seculares tenham logrado alcançar alguns êxitos em abrir espaços significativos para a laicidade do Estado, esse sistemático pertencimento às tradições religiosas rendeu e ainda rende esses frutos consubstanciados em legislações que estabelecem, como normas jurídicas, esses postulados religiosos. Este processo se acentua, agora, em plenas democracias que se afirmam como representativas, em que um número expressivo de legisladores, legitimados pelo voto direto, se incumbem da tarefa de 
elaborar leis em que a moralidade própria de suas concepções religiosas acabe por transformar a laicidade do Estado em um aspecto relativo, se não, em alguns casos, meramente formal.

Nesse sentido, Maria das Dores Campos Machado, especialista em sociologia da religião, Professora da Universidade Federal do Rio de Janeiro, em matéria publicada, traz um alerta, em que aborda o avanço da Bancada Evangélica na Câmara dos Deputados, ao referirse que, em votações importantes, ocorrem alianças entre segmentos religiosos evangélicos, com católicos e mesmo com espíritas:

\begin{abstract}
Nos últimos anos, a atuação da bancada evangélica na Câmara dos Deputados tem se mostrado com bastante força no noticiário nacional. Eles conseguiram avançar em propostas mais conservadoras, como a retirada da palavra "gênero" no Plano Nacional de Educação, realizaram audiências e comissões para tentar barrar qualquer direito da comunidade LGBT (lésbicas, gays, bissexuais, travestis e transexuais), bem como das mulheres: as vitórias dos religiosos se devem a alianças feitas com parlamentares católicos e espíritas. A primeira coisa a se dizer é que, quando você entra no site da Frente Parlamentar Evangélica, você vê 193 nomes. Mas ali tem o nome de todo mundo que assinou para se criar a Frente Parlamentar Evangélica. Tem vários católicos, por exemplo. Os evangélicos assinam também para outros, como a Frente Parlamentar Católica, a da Segurança Pública etc. Para o público em geral aparece como se eles tivessem um peso muito grande, mas eles não têm. Os evangélicos são hoje $16 \%$ do Congresso, mas aparecem com essa força toda porque são muito articulados e assertivos, têm uma postura muito beligerante e fazem aliança com vários segmentos que também são conservadores, o que fez com que eles, nos últimos anos, se fortalecessem. (MACHADO, 2017).
\end{abstract}

Não se trata, aqui, de discutirmos as causas do avanço dessas propostas conservadoras, de cunho moralizante, baseados nos postulados morais que suas agremiações religiosas específicas defendem, mas de tão-só corroborar o entendimento de que, efetivamente, nesses temas, as diversas facções de fundamentalismos religiosos se unem e, dessa forma, ameaçam a própria laicidade do Estado, ainda que esse caráter laico esteja alicerçado em princípios constitucionais positivados em nossa Carta Política. Podem ser numericamente minoritários, mas enquanto muito bem articulados, podem impor seus postulados à maioria da população, pela atividade própria de legislar.

Nesse passo, mister se faz um retorno à apresentação dos postulados vigentes em nossa atual Constituição, relativamente ao tema em discussão, notadamente, para evidenciar o problema de não se ter um limite claramente estabelecido no que diz respeito ao acesso a essas parcerias do Estado com as respectivas religiões; precipuamente se a confrontarmos com a já referida expressa vedação do art. 19, cujo texto impede esse tipo de associações, exceto quando determinadas por lei, ou se esta colaboração for de interesse público. Eis o desafio de se manter 
a laicidade do Estado, haja vista que tais Parlamentares são legisladores, logo, investidos da legitimidade e da legalidade para legislar e, além disso, para poderem estender quaisquer entendimentos acerca dos significados dessa parceria em benefício do interesse público.

Nesse sentido, ganha relevo a afirmação de Supiot, de que tais fatos demonstram que o campo religioso da fé, esteve essencialmente ligado à lei e à deliberação pública:

(...) o fato de o cristianismo ter hoje perdido, em certos estados ocidentais, seu lugar constitucional, não significa, em absoluto, que esses estados estão desprovidos de fundamentos dogmáticos. (...) os Estados, assim como as pessoas, continuam a ser sustentados por certezas indemonstráveis, por verdadeiras crenças, que não procedem de uma livre escolha, pois elas participam da identidade deles. (SUPIOT, 2007, p. 16).

Adentrando o campo normativo específico, o texto constitucional dispõe, em seu art. 5, VI (C.F./88), a inviolabilidade da liberdade de consciência e de crença, com livre exercício dos cultos religiosos e proteção aos locais de culto e suas liturgias, desde que nos limites da lei. Trata-se de uma liberdade negativa, haja vista que o Estado não pode, aqui, intervir no campo subjetivo de eleição de quem quer que seja; entretanto, deve, a seu turno, assegurar a proteção de quaisquer cultos e de suas liturgias, mormente em casos de agressão, impedindo que certas agremiações ou cultos venham a tentar subjugar uns aos outros, ou intervir de quaisquer formas no livre desempenho de funções dos demais. No mesmo art. 5º, agora no inciso VII (C.F./88), chega-se a uma determinação de prestação positiva do Estado, já que o texto determina que fica assegurado, nos termos da lei a prestação de assistência religiosa nas entidades civis e militares de internação coletiva. Essa determinação reveste-se de significado, por demonstrar que o Estado chama a si a tarefa de assegurar a prestação de serviço religioso aos internos em instituições dessa natureza, em uma clara importância que o Estado dá ao caráter religioso das pessoas, ou seja, neste caso, laicidade não significa que o Estado se tenha tornado ateu.

A seu turno, a redação do inciso VIII, do mesmo art. $5^{\circ}$ (C.F./88) estabelece a preservação de direitos em questões de consciência, a também chamada escusa de consciência, que se torna problemática, na medida em que não fica claro o limite entre os campos de ação individual e obrigações coletivas, como bem assevera Bulos:

Convém ressaltar que a preservação de direitos em questões de consciência pode ser exercida com relação a quaisquer obrigações coletivas que conflitem com as crenças religiosas ou convicções político-partidárias do indivíduo, não podendo, entretanto, ser anteparo para a rebeldia, preguiça ou ócio daquelas pessoas que, descumprindo a lei, desejam livrar-se de obrigações a todos imposta. (BULOS, 2007, p. 434). 
$\mathrm{Na}$ verdade, essas possibilidades acabam escoando aos Tribunais, para que estes decidam quanto à correta aplicação do direito constitucional de escusa de consciência, uma vez que isto se torna problemático quando, por exemplo, funcionários públicos, integrantes de agremiações religiosas, se negam a reconhecer casamentos entre pessoas do mesmo sexo, alegando essa possibilidade, uma vez que, enquanto órgãos do Estado, presentificam as decisões públicas desse mesmo Estado, de forma que não se podem furtar a uma decisão estatal desse nível, conforme consta de deliberação do Conselho Nacional de Justiça/2013. Não se trata, aqui, de desenvolver os inúmeros casos em que pode ocorrer a escusa de consciência, mas de tão-só deixar o alerta de uma possível brecha da lei, por onde podem se consubstanciar uma série de desrespeitos aos próprios ditames constitucionais.

Assim, os desafios à manutenção da conquista histórica da laicidade do Estado se revestem de importância, como já referido, na medida em que: “em que pese a conotação laica do Estado, este não é neutro em relação à religião, justamente pelo fato de seu corpo político ser formado por pessoas que a possuem.”(DOOYEWEERD, 2010, p. 2650). Por conta disso, os integrantes desse corpo político, com legitimidade para legislar, acabam por exteriorizar, em suas leis e atos normativos, o viés religioso, respeitando o credo das pessoas e de suas práticas religiosas determinadas, incorporando algumas delas em leis específicas, com o intuito de visar à facilitação da vida em sociedade e igualar direitos. (ANDREUCCI, 2012, p. 97).

Nesses casos, entretanto, há que se ressaltar que certos grupos religiosos, uma vez municiados dessa legitimidade podem estar interessados no processo contrário, isto é, não o de igualar direitos, mas de impor os seus princípios à maioria da população não mobilizada e, inclusive, promover retrocesso em conquistas de direitos já obtidos. Ratificando tais entendimentos, chega-se a identificar "a perceptível influência religiosa nas decisões políticolegislativas, pois os representantes do povo - que possuem religiosidade - acabam formulando fundamentos dogmáticos sustentados por certezas indemonstráveis, por crenças religiosas, que fazem parte de suas próprias identidades, melhor formulando exteriorizações daquilo que eles acreditam ser a Verdade.” (SCALQUETTE, 2013, p. 203).

O problema está aqui: se lograrem êxito nessa atividade, estaremos diante de leis que devem ser respeitadas por todos.Isto se torna problemático quando não respeitado pelos Julgadores, em sua integralidade, mas, não menos pior, entretanto, quando ocorre que determinados grupos religiosos, bem aparelhados em termos de legitimidade para agir em nome 
do Estado, como no caso dos legisladores, sinalizam esse endosso estatal em termos de coerção, dado que esta é a função da lei, ou seja, a de ser cogente, ferindo, pela base, essa laicidade, ao impor seus postulados religiosos aos demais que deles não comungam.

\section{ENSINO CONFESSIONAL NA ESCOLA PÚBLICA}

Infelizmente, o desafio de preservar a laicidade não se resume aos legisladores, como se pode demonstrar até o presente momento, mas está devidamente instalada no próprio poder jurisdicional do Estado, inclusive na mais alta corte do país, o Supremo Tribunal Federal, que deveria realizar sua função de, como Tribunal Constitucional, preservar a laicidade no país, acaba de tomar, por votação apertada, a equivocada decisão de autorizar, no Brasil, o ensino religioso confessional nas escolas públicas. Essa decisão responde ao pedido de Ação Direta de Inconstitucionalidade $\mathrm{n}^{\circ}$ 4439, formulado pela Vice Procuradoria Geral da República, no sentido de que o STF interpretasse conforme a Constituição os dispositivos legais apresentados, para assentar que o ensino religioso em escolas públicas só pode ser de natureza nãoconfessional, com a não admissão de professores na qualidade de representantes das confissões religiosas. (ADI 4439/2010). A ação foi proposta pela Procuradora Deborah Duprat ao afirmar que o ensino religioso no país aponta para a adoção do “ensino da religião católica”, fato que afronta o princípio constitucional da laicidade. Este caráter majoritário se refere, por óbvio, à nossa própria formação histórica, mas o problema está em, igualmente, respeitar as minorias, em um país que também apresenta enorme diversidade cultural. Entretanto, o ensino religioso está previsto na Lei de Diretrizes e Bases da Educação Nacional e no Decreto 7.107/2010, acordo assinado entre o Brasil e o Vaticano para o ensino do tema. No geral, a resposta da maioria dos Magistrados foi no sentido de que o educador tem a liberdade de promover suas crenças em sala de aula, ou seja, lecionar como representante de uma religião.

Este tema vem causando ainda grande repercussão, dado que os debatedores se dividem entre os defensores do Estado laico e, portanto, são críticos dessa decisão; e os pertencentes às diversas confissões religiosas, que o apoiam, ou ainda dos que sustentam que a laicidade não se vê ferida, em função de que tal ensino foi posto como opcional: o problema nesse caso se refere, em suma, à forma como esse caráter de opcional deve ser realizado,assim como a maneira com que o Estado poderá, de sua parte, como obrigatoriedade, oferecer ensino religioso de acordo com todas as opções subjetivas dos postulantes a receberem tal ensino. 
Assim, por se defender, aqui, o caráter laico do Estado, se está inserido na corrente crítica, ou seja, no sentido de que tal decisão afronta o princípio constitucional, sendo que a situação se torna ainda mais gravosa em função de que, por ser uma decisão do STF, nesse ponto, por ora, não cabe mais nenhum grau de recurso para reverter essa determinação. Não se trata de apresentar uma exposição exaustiva dos votos dos Ministros, mas de apresentar o posicionamento mais lúcido da corrente crítica, que entende, nessa decisão, uma agressão à laicidade do Estado. Nesse sentido, posicionou-se Carlos Cury, ao sustentar que:

(...) o risco do ensino religioso confessional é de a sala de aula ser um lugar de recrutamento. Este, inclusive, é o motivo pelo qual a ação foi proposta em 2010, pela então Vice Procuradora Débora Duprat. Ela moveu a ação porque, no seu entendimento, o ensino religioso atual aponta para a adoção do ensino da religião católica, fato que afronta o princípio constitucional da laicidade. Isso, na prática, acaba acontecendo. Apesar de a lei não obrigar o ensino confessional, temos uma larga tradição católica de longo tempo, sobretudo no Império, quando o Brasil era uma colônia, quando se criou uma cultura católica muito profunda. A escola é um lugar em que se deve aprender a respeitar o diferente. Há famílias ateias, agnósticas e de religiões africanas e quando se firma uma confissão religiosa, de alguma maneira, se cria uma distinção entre os alunos. (CURY, 2017).

Na esteira de seu voto, o Ministro Luís Roberto Barroso traz um importante esclarecimento acerca do que já se afirmou, anteriormente, a respeito das citadas associações do Estado com as religiões, pautadas pela definição de interesse público, que recebe a denominação através do brocado jurídico amici curiae, isto é, amigo da corte, no sentido de que as religiões, aqui, poderiam, sobremaneira, contribuir com o ensino de uma maneira geral, o que, sob o aspecto formal poderia significar benefício ao sistema geral de ensino; mas que, na prática, revela outra de suas faces mais ameaçadoras aos próprios princípios constitucionais de liberdade religiosa. Essas afirmações expressam, claramente, as dimensões que o tema já vem assumindo na realidade brasileira:

Não existe um mecanismo que contribua para que o conteúdo do ensino religioso seja transmitido sem proselitismo e com respeito à liberdade religiosa dos alunos em todas as escolas de ensino fundamental no Brasil. Em decorrência disso, não são raros os relatos de discriminação de cunho religioso, muitas vezes graves e envolvendo até violência física, em especial relacionados às religiões de matriz africana. De acordo com relatório produzido pela Relatoria dos Direitos Humanos à Educação da Plataforma DHesca, em razão do recebimento de denúncias sobre casos de discriminação de cunho religioso nas escolas, (e)ntre as denúncias que chegaram à Relatoria, de diversas regiões do país, encontram-se casos de violência física (socos e até apedrejamento) contra estudantes; demissão ou afastamento de profissionais de educação adeptos de religiões de matriz africanas ou que abordaram conteúdos dessas religiões em classes; proibição de uso de livros e do ensino da capoeira em espaço 

religiosas, em prejuízo das vinculadas à matriz africana; omissão diante da discriminação ou abuso de atribuições por parte de professores e diretores, etc. (BARROSO, Voto, ADI 4439, 2017).

Eis um claro desafio à aplicação da hermenêutica da diversidade, haja vista que, em termos constitucionais, a própria laicidade do Estado não impede certas ações que impliquem na colaboração com entidades religiosas, mas que devem se focar, sempre, em definições de aspectos culturais e sociais, de forma geral, como historicamente presentes em nossa formação como país; ou seja, o caráter laico se mostra, assim, como relativo. Entretanto, deve ser entendido como norma constitucional, de forma que deve ser aplicado a partir de argumentos não religiosos, no sentido de que não podem implicar em favorecimento de grupos religiosos muito melhor aparelhados, capazes de transformar o ensino religioso em aliciamento de fiéis, notadamente na escola pública, cujo ensino religioso deveria pautar, sempre, por um ensino neutro. Este ensino neutro, ou que, pelo menos, se proponha a seguir por neutralidade, deve se orientar no sentido, por exemplo, de se evidenciarem os postulados da diversidade religiosa, enfocando seus princípios e caráter histórico, ao invés de abrir a possibilidade para que dogmatismos religiosos de quaisquer naturezas invadam o espaço público, haja vista que sacerdotes de quaisquer matizes terão enormes dificuldades de efetivar esse caráter neutro, tendendo, efetivamente, a fazer proselitismos.

\section{CONSIDERAÇÕES FINAIS}

Colocar-se ao lado da laicidade do Estado significa apoiar uma conquista de vários séculos de lutas para impedir o domínio de preceitos religiosos na esfera pública, para evitar os trágicos exemplos históricos que sobejam, quando determinadas agremiações religiosas, invocando seu maior número de participantes, assumem o comando de certas atitudes do Estado. Historicamente, nesses casos, o que ocorreu foi no sentido de sufocar, reprimir, ou até mesmo de fazer desaparecerem outras manifestações religiosas, o que se torna inadmissível em um país como o Brasil, marcado por séculos de diversidade cultural e, logo, de diversas manifestações de culto, em todos os seus aspectos.

Além disso, fica o alerta acerca das agressões à laicidade do Estado perpetradas, como já mencionado, por minorias religiosas que, valendo-se de seu acesso à representação dos poderes políticos de nossa democracia representativa, usem destes poderes para imporem leis 


\section{O RESPEITO À DIVERSIDADE CULTURAL-RELIGIOSA PELO CARÁTER DE LAICIDADE DO ESTADO: UMA CRÍTICA HERMENÊUTICA AO ENSINO CONFESSIONAL NA ESCOLA PÚBLICA}

gerais, ao contexto da maioria da população, tratando de seus postulados como se fossem verdades inquestionáveis. Essa discussão, que se foca na questão do ensino confessional na esfera pública, outra função não tem do que deixar esse alerta, no sentido de uma correta aplicação do que se denomina de interpretação conforme a Constituição, ainda que os dignitários da Suprema Corte tenham entendido, a contrário senso, permitir que essa forma de ensino prospere, indo de encontro ao que o próprio texto constitucional afirma, de maneira clara.

Nesse sentido, se afigura como correta e necessária uma educação que seja pautada pela tolerância religiosa, como forma de procurar, pelo menos, diminuir os conflitos que possam surgir e que surgem dessa diversidade cultural constitutiva de nosso país, sem quaisquer tipos de privilégios assegurados a grupos majoritários, ou que estejam melhor organizados, que venham a sufocar, ou constranger outras manifestações religiosas enquadradas em definições de minorias, dado que este é o verdadeiro aspecto de uma sociedade que se definiu, constitucionalmente, como Estado Democrático de Direito. Por conta disso, se entende que a possível superação, ou uma forma de minimizar esses conflitos que irrompem em nosso contexto, seria uma correta aplicação do caráter de laicidade do Estado brasileiro, como o define a própria Constituição Federal, para que tal disposição deixe seu caráter formal e se insira em práxis jurídica cotidiana.

O princípio para realizar essa mudança paradigmática, desde o enfrentamento necessário da esfera pública, para que os legisladores não respondam somente aos seus grupos de interesses específicos nessa área, mas que pautem sua ação legislativa no sentido do respeito à vontade geral e ao equilíbrio da própria sociedade, passa inexoravelmente, por uma educação que se alinhe com essa proposta de evidenciar a pluralidade, a heterogeneidade e multiplicidade dos aspectos religiosos performativos de nossa índole como nação. O mesmo princípio se pode aplicar a todos os operadores do Direito, notadamente aos seus aplicadores, em todas as instâncias, abandonando o solipsismo de suas decisões, para focá-las, igualmente, nessa variedade de manifestações, preservadas pela laicidade do Estado.

Da mesma forma, a educação deve ser pautada pelo diálogo entre essas diferentes manifestações religiosas, de forma a não serem segmentadas em nichos em que somente se ensinem as mesmas práticas específicas de cada uma. Uma sociedade plural se forma na escola aberta para a tolerância e para o diálogo interconfessional múltiplo, não isolado. As questões 
envolvidas nessa pretensão revelam-se em uma enorme complexidade, mas que precisa ser discutida e não mascarada, de forma simplista, para que os legisladores e os aplicadores do Direito, igualmente, sejam tomados pelo caráter de diversidade, como em uma abertura voltada para a compreensão do diverso e não para a sua submissão aos seus postulados próprios. Por conta disso, o Direito, como um todo seria enormemente enriquecido por essa mesma diversidade, desde que cumprindo com os ditames de laicidade do Estado, uma vez devidamente aplicado ao contexto social que o erigiu enquanto tal.

\section{REFERÊNCIAS}

ANDREUCCI, Ana Cláudia Pompeu Torrezan. Igualdade de gênero e ações afirmativas: desafios e perspectivas para as mulheres brasileiras pós-constituição Federal 1988. São Paulo: LTR, 2012.

BETIOLI, Antônio Bento. Introdução ao Direito: lições de propedêutica jurídica tradicional. 11 ed. São Paulo: Saraiva, 2011.

BRASIL. CONSELHO NACIONAL DE JUSTIÇA. Resolução No 175 de 14/05/2013. Dispõe sobre a habilitação, celebração de casamento civil, ou de conversão de união estável em casamento, entre pessoas de mesmo sexo. Disponível em: http://www.cnj.jus.br/atosnormativos?documento=1754. Acesso em: 09 fev. 2018.

BRASIL. Constituição Federal/88. Disponível em http://www2.camara.leg.br/legin/fed/ consti/1988/constituicao-1988-5-outubro-1988-322142-publicacaooriginal-1-pl.html. Acesso em: 05 fev. 2018.

BRASIL. SUPREMO TRIBUNAL FEDERAL. Ação Direta de Inconstitucionalidade - ADI 4439/2010. Disponível em http://www.stf.jus.br/portal/geral/verPdfPaginado.asp?id $=635016 \&$ tipo $=$ TP\&descricao=ADI\%2F4439. Acessada em 07.02.2018.

BRASIL. SUPREMO TRIBUNAL FEDERAL. Ação Direta de Inconstitucionalidade - ADI 4439/2010. Voto do Ministro Luís Roberto Barroso. Versão final. Disponível em: http://luisrobertobarroso.com.br/wp-content/uploads/2017/08/ADI-4439-vers\%C3\%A3ofinal.pdf. Acesso em: 09 fev. 2018.

BULOS, Uadí Lammêgo. Curso de Direito Constitucional. São Paulo: Saraiva, 2007.

CAMARGO, Margarida Maria Lacombe. Hermenêutica e Argumentação: uma contribuição ao estudo do Direito. $3^{\text {a }}$ ed: rev/atual. Rio de Janeiro: Renovar, 2011.

CANFÃO, Olívio Albino. Métodos de interpretação jurídica à luz do horizonte hermenêutico. Revista de Direito UNIFACS. No 158. 2013. Disponível em <http://www.revistas.unifacs.br>. Acesso em: 19 fev. 2018. 
CURY, Carlos Roberto Jamil. O debate do ensino religioso confessional. Disponível em: $<$ http://www.huffpostbrasil.com/2017/09/27/stf-decide-pelo-ensino-religioso-confessionalobrigatorio-nas-escolas-publicas-do-pais_a_23224556/>. Acesso em: 08 fev. 2018.

DOOYEWEERD, Herman. No crepúsculo do pensamento ocidental: estudos sobre a pretensa autonomia do pensamento. Trad. Guilherme Vilela Ribeiro e Rodolfo Amorin Carlos de Souza. São Paulo: Hagnos, 2010.

FRANÇA, Rubens Limongi. Hermenêutica Jurídica. $7^{\text {a }}$ ed. São Paulo: Saraiva, 1999.

MACHADO, Maria das Dores Campos. Os parlamentares religiosos tendem a ser mais conservadores do que a população evangélica. Disponível em: https://brasil.elpais.com/brasil/ 2017/12/02/politica/1512221378_127760.html. Acesso em: 07 fev. 2017.

MAXIMILIANO, Carlos. Hermenêutica e aplicação do Direito. Rio de Janeiro; Forense, 2013.

SCALQUETTE, Rodrigo Arnoni. História do Direito: perspectivas histórico-constitucionais da relação entre Estado e Religião. São Paulo: Atlas, 2013.

SILVA, Sérgio André R.G da. A Hermenêutica Jurídica sob o influxo da Hermenêutica Filosófica de Hans-Georg Gadamer. Revista Tributária e de Finanças Públicas. V. 64. p. 276/296, set/out.2005. Disponível em: <http://www.revistadostribunais.com.br>. Acesso em: 16 fev. 2018.

STRECK, Lênio Luís. Bases para a compreensão da Hermenêutica Jurídica em tempos de superação do esquema sujeito-objeto. Sequência Estudos jurídicos e políticos. V. 28 (54). Disponível em http://www.Periódicos.Ufsc.br/index.php/sequencia/article/view/ 15066/137332. Acesso em: 20 fev. 2018.

STRECK, Lênio Luís. Hermenêutica e Jurisdição: diálogos. Porto Alegre: Livraria do Advogado, 2017.

SUPIOT, Alain. Homo juridicus: ensaio sobre a função antropológica do direito. Trad. Maria Ermantina de Almeida Prado Galvão. São Paulo: WMF Martins Fontes, 2007.

VENOSA, Sílvio de Salvo. Introdução do estudo do Direito: primeiras linhas. $4^{\text {a }}$ ed. São Paulo: Atlas, 2014. 